\title{
Analysis on Children Custody Decision Making Model
}

\author{
Yi. Gu ${ }^{1}$, Guangming. Zhang ${ }^{2}$ \\ 1 The Kenneth Wang School of Law, Soochow University, Suzhou, China, 215006 \\ 2 The School of Computer Science \& Technology, Soochow University, Suzhou, China, 215006 \\ Email: hfxq.2007@163.com,gmwell@gmail.com
}

\begin{abstract}
Children custody disputes are complicated for many judges owing to so many dynamic factors should to be considered. This paper proposes a novel model for legal expert system Based on LVQ Neural Network. Firstly, all clauses and discretionary factors, extracted from theories and judicial practice, involved with custody disputes in divorce were quantified to obtain related set elements. Then the LVQ neural network was applied to construct a model for children custody disputes weight vector analysis on the set elements. Ultimately, the weight vector close to decision boundaries between classes could promote the classification performance. Accordingly, the performance of the LVQ by generating weight vectors close to decision boundaries is higher. By testing, custody disputes legal expert system could consider all relevant circumstances from a good all-around point of view and effectively.
\end{abstract}

Keywords- legal expert system; custody disputes;neural network; best interest of child

\section{INTRODUCTION}

One of the most difficult judicial verdicts facing a judge is the determination of child custody when the marriage disintegrated. Since more emphasizes imposed to child development, the Marital Law adopted only principle of contested custody-Best interest of child [1-3]. However the elusive criterion is rather a complicated balancing of numerous competing factors, many of which are highly subjective and emotional. In this respect, judges are actually playing God by making decisions about child's future arrangement based on limited facts support, which subtle personal bias may cause calamity to child. Compared with US courts that have developed a series of specific standards in response to these practical difficulties, Chinese marital law depicted the vague formula of custody decision, with only one principle in marital code and no more than 6 clauses of judicial interpretations on this issue, and hence under the shadow of statutes, left the substantial discretionary power to judge[4-7]. Although indeterminacy of custody standards permits judges to individualize case treatment and give expression to their own conscience and righteousness involved in child welfare, the absence of firm guidelines has so widened the discretion that judges are treading on uncertain ground with their own values and moral judgment. In general, combinations and values of factors are hard to enumerate or to calculate, nevertheless, judges will probably apply, consciously or unconsciously, some framework within which to weight every possible circumstance as a practical matter. This evoked our interest to build a judicial assistant expert system to uncover the process of reasoning when a judicial decision upon child custody is made. In this knowledge base, we tried to identifying "all factors" relevant to child welfare and parents' specific conditions and then weigh the importance of each factor by analyzing 150 unreported typical cases, granted by the Suzhou Intermediate People's Court and investigating 20 senior judges in this field. After the comparison of different criterions in US (namely psychological parent, primary parent, and approximation standards for determining the best interest of children), author proposed a synthetical model integrating the merits of other standards under the frame of Chinese current marital law. By applying this model, skilled experts like judge and solicitor can be assisted to make comprehensive and scientific consideration, whereas parties competing for custody, with little or non legal knowledge can be helped to settle typical disputes.

Neural network is composed of a number of nodes, or units, and connected by links. Each link has a numeric weight associated with it[8]. Weights are the primary means of long-term storage in neural networks, and learning usually takes place by updating the weights. Some of the units are connected to the external environment, and can be designated as input or output units. The weights are modified so as to try to bring the network's input/output behavior more into line with that of the environment providing the inputs. The idea is that each unit does is that each unit does a local computation based on inputs from its neighbors, but without the need for any global control over the set of units as a whole. In practice, most neural network implementations are in software and use synchronous control to update all the units in a fixed sequence.

Learning Vector Quantization (LVQ) neural network [910] could perform intrusion alert clustering on the purified intrusion dataset. LVQ have several advantages. Firstly, LVQ has higher classification accuracy. LVQ uses preassigned cluster labels to training samples, which can minimize the average expected misclassification probability. Secondly, LVQ has no obstacle in dealing with the large dataset. Thirdly, the optimized LVQ algorithm can learn faster than the BP model which often suffers from the slow learning process and the difficulty in reaching convergence.

The rest of this paper is organized as follows. The concept of LVQ neural network is given in section II as preliminary work. The custody disputes model based on LVQ neural network is given in Section III. The discussion 
of the results is given in Section IV. Section V concludes the paper and points out the directions of future work.

\section{LVQ NEURAL NETWORK}

Neural network is used to classify the extracted vectors. We use Learning Vector Quantization (LVQ) model due to its low complexity and high learning capability.

The LVQ is simple and faster than the error backpropagation algorithm, which is the most popular neural network model. However, the learning speed and classification performance of the LVQ are sensitive to the initial weight vectors. A simple method of initializing the weight vectors is to take the first $m$ training vectors and use them as the initial weight vectors; the remaining vectors are then used for updating the weight vectors. Sometimes, the weight vectors are initialized to randomly select training input vectors or the mean of the training vectors of each class.

In the LVQ, an appropriate initial weight vector improves the learning time and classification performance. However, the distribution of initial weight vectors chosen by the previous initialization methods does not have large difference from the distribution of the training vectors. This is good for vector quantization. When a nearest neighbor classifier is used, an input vector is classified to the class represented by the weight vector closest to it. Therefore, when we classify an input vector using weight vectors with uniform distribution, only weight vector close to decision boundaries between classes contribute to the classification performance.

Accordingly, we can improve the performance of the LVQ by generating weight vectors close to decision boundaries and by removing unnecessary weight vectors.

Based on this fact, we propose a new weight initialization method for the LVQ, which generates the weight vectors close to decision boundaries.

The proposed method is as follows:

[Step 1] Among training vectors of each class, take the first vector and use it as a weight vector for the class. The values of the remaining weight vectors for the classes are set to zero.

$$
\mathrm{Q}_{1}^{\mathrm{k}}=X_{1 \text { for }}^{k} k=1,2, \cdots, M
$$

where $X_{1}^{k}$ is the first training pattern of the k-th class, $Q_{1}^{k}$ is the first weight vector for the k-th class, and $M$ is the total number of classes.

[Step 2] Feed a new training vector as an input vector into the network.

[Step 3] Compute the distances between the input vector and the weight vectors.

$$
d(k, j)=\sum_{i=1}^{N-1}\left(X_{i}-Q_{i, j}^{k}\right)^{2}
$$

where $X_{i}$ is the i-th element of the input vector, $Q_{i, j}^{k}$ is the i-th element of the $\mathrm{j}$-th weight vector for the k-th class, and $\mathrm{N}$ is the dimension of the input vector.

[Step 4] Determine whether the class represented by the weight vector with minimum distance is the same with the class of the input vector. Only if two classes are different, the input vector is assigned as a new weight vector for the class of the input.

[Step 5] Repeat Step 2-4 until all of the training vectors are processed.

Whereas for the original LVQ the number of the weight vectors for each class is to be predetermined, the proposed algorithm automatically determines the number of the weight vectors as the learning proceeds.

\section{CUSTODY DISPUTES MODEL}

Logical model construction is a pivotal part in legal expert system, which contains statutes as well as selected discretionary factors as set elements.

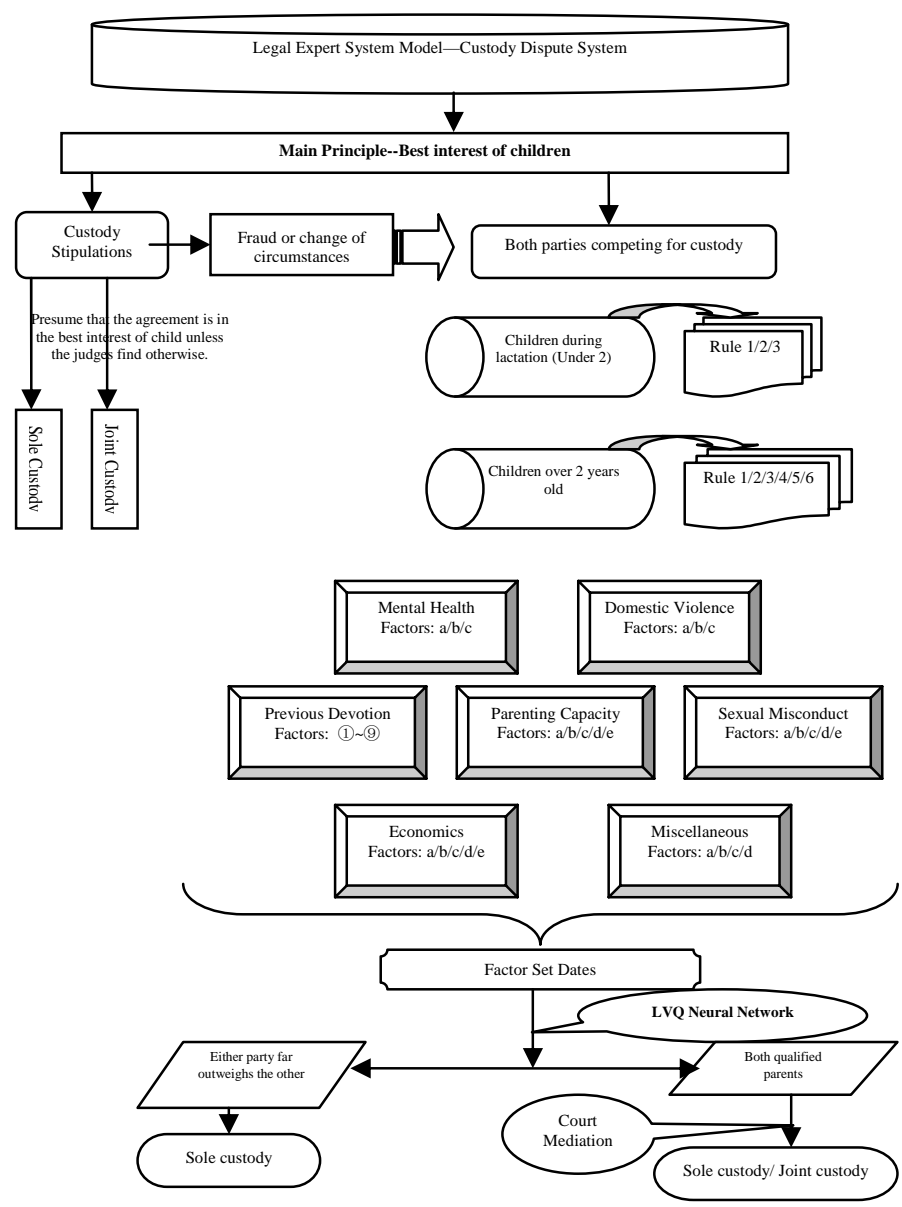




\section{Figure 1. Children custody disputes Process}

In accordance with Chinese marital law, if any dispute arises concerning which party shall bring up the children after the dissolution of the marriage, it is the legal presumption that the children during lactation shall be brought up by their mother, unless she is proved unfit; for children beyond lactation, such dispute shall be settled by the court taking the interest of the children and specific conditions of both parties into consideration. This provision, a fundament of all circumstances that enter into judicial evaluation, has been described as the main principle in custody determination--best interest of children.

Divorcing parents are encouraged to make an agreement about the future custody of their children, and the court would presume that the settlement is in the best interests of children unless the judges find otherwise, since no one is more clear than parents themselves the interest of own child. In anther word, respecting the real intentions of parents, the valid contract would bind both parties if no fraud or substantial change of the circumstances involved in the aforementioned agreement.

With regard to those who failed to reach the custody agreement after divorce and competing for the custody award, the Judicial Interpretation of Supreme Court provided following basic guidelines on this issue.

As for children under two years old, maternal custody is unfit if--

(1)The mother suffers from incurable contagious pathema or other grievous pathema, makes the custody incapable for her.

(2)The mother who has the capability to rear the child is unwilling to assume the obligation, and the father claims for the custody

(3) Others.

As for juveniles over two years old, both parties contending for the custody, any party under any of following circumstances shall be favored by the court if--

(1)Being sterilized for the sterilization or any other reasons

(2)The child being brought up by the individual spouse, and hence the change of environment would exert significant detriment to interest of child

(3)The party has no other child excepting the contested child, while the counterparty has additional child

(4)Either of the party is more beneficial to the child, while the other party proved incapable due to grievous pathema or other reasons that are adverse the growth of child

When both parents fit for child rearing, competing for the custody, the party whose parents, which means grandparents or maternal grandparents, being residing with the child during the marriage, are capable and willing to help rear the child, is favored by the court.

If any custody disputes arise for the child over 10 years old, the willingness of child should be take into consideration. [11-12]

This judicial interpretation has been criticized for its scattered view, no guidance about comprehensive factors nor about the relative weight of individual factors, therefore, author decided to establish a considerably complete framework containing numerous discretionary factors to assist judges in decision making processing. With reference to under-mentioned circumstances, the judge can exercise his own discretion in deciding the custody award, being confined or subjected to conscience and righteousness only.

\section{Mental health}

A child's development needs the continual emotional contact with custodial parent whose mental condition is crucial to the health of child.

a. Suicide attempt. In spite of great sympathy showed to people committing suicide, no judge would risk to place child with whom is struggling at the edge of mental collapse.

b. Hospitalization for mental reasons. Severe mental problems made parent unable to assume the responsibility of custody

c. Emotional stability. When the party suffers from bitterness after divorce, and hence failed to separate interpersonal anger from the parenting role, the child-parent psychological relationship is precarious.

\section{Sexual misconduct.}

Generally court holds that a parent's promiscuous conduct or lifestyle, no matter during the marriage or post divorce, cannot be neglected in custodial decision making.

a. Sexual crime. Sexual crime including bigamy and other most grievous sexual misbehavior, which also being regarded as a crime to his or her own family, it is an experimental praesumptio that the feasor is unqualified. Situation differs for those who were sentenced to criminal detention or imprisonment can no longer assume the custody for being deprived freedom, while for those sentenced to public surveillance, would have strict access to custody.

b. Sex trade, malfeasance infringes the administrative regulations. This misconduct may have devastating consequence on the family integrity and the parent-child relationship.

c. Adultery. The adultery is a reflection of a parent's moral standard, thus the extramarital affair itself is a proof of lacking sense of family responsibility. Since the moral environment in which the child will be reared is vital significant consideration of the court that is why judges are convinced adultery could have a deleterious effect on a child's development of being brought up by a defective character. 
d. Unmarried cohabitation with a romantic partner. Given contemporary moral standards, it is inappropriate to cohabitate with a romantic partner post divorce in the presence of child.

e. Homosexuality. Being a homosexual per se cannot be proved unfit for custody, and it is hard to make a moral evaluation on this issue, the court hesitate to grant the custody to homosexual parent cause there is a high risk that the public would subject the child to ridicule and embarrassment, if he reside with admitted homosexual.

\section{Economics}

There used to be an exaggerated concern on the economic condition of both parents, being financially better off, the party was supposed to be more capable to cope with material needs of child. However income level or economic advantage is not a permissible basis for custody decision making, since there is no assured correlation between wealth and parenting quality. Following non conclusive factors still would influence the judge to some extent:

\section{a. Adequate income.}

It is generally believed that the party earns more than the average wage level in local area is financially adequate for child rearing. If the party is insufficient to provide proper care, the remedy is to grant child support instead of depriving custody.

\section{b. Job stability.}

Stable and harmonious environment is essential for the interest of child, and therefore the excessive job change could exert unsafe and unstable feeling to child.

\section{c. Disposition of family assets.}

The judge is always cautious about the life style to prevent child being inappropriately affected by prodigus.

\section{d. House and community.}

The court is also concerned about condition of the house that each parent could provide, including the size, location, cleanliness of dwelling, and the community they live in. In order to prevent the unfair favoring based on financial strength by awarding custody to whom has better and luxurious dwelling, the size of house should be considered only in the sense of sufficient for the child to reside in.

Compared with the size, judges pay more attention to the location and the environment of the community, which directly related to the educational opportunities and level of public facilities. In addition, there is no denying that the urban-rural disparity and areal variation in China are incredibly huge in all aspects. That is quite apprehensible why most of judges are prone to establish child in more developed place or city center with easier access to public service and better schools instead of rural area.

Some commentators criticize that the multiplicity of attachments makes it impossible to base residence decisions on this factor alone. In other words, living in the city or countryside reflects different life attitudes that should be equally respected. Although the freedom of choosing one's own lifestyle should be guaranteed and respected, for juveniles lacking the capacity of will, their life have to be decided by judge for children's interest. By prefer certain location with better environment and more social resources, this consideration follows common sense and benefits them.

\section{e. Frequency of relocation}

The custodian has the responsibility to preserve a stable and nurturing family environment for children after divorce, living in the same community, attending the same school and maintaining consistent peer relationships would significantly alleviate the negative consequence of family dissolution on children. The judges never consider in a vacuum, permanent house is impractical for any party, but excessive relocation should be avoided, unless it far outweighs the advantages.

\section{Parenting capacity}

\section{a. Education background}

Although different philosophies of life and life pattern should be respected and judge cannot make the decision directly upon education background of both parents, it does reflect parenting capacity to some extent, especially in domestic education and discipline. It seems that residing with a parents well educated with better social condition, the child could benefit from better educational and professional opportunities if the child wishes. Such external superiorities shouldn't be exaggerated because we have witnessed so many cases that these advantages being meaningless without the internal emotional recognition.

\section{b. Child-parent relationship}

According to empirical presumption, it seems that mothers are more competent for tackling with emotional issue of child for their sensitive nature, whereas fathers are less capable to handle this situation for their negligent characteristics. However the gender bias is groundless and each family differs in every single detail, the judges are accountable to figure out the relation between child and individual parent. Whoever is more willing to communicate with child, has consummate skills of persuasion and discipline, and more thoughtful towards child's needs physically and mentally shall be favored.

\section{c. Communication with non custodial parent}

Best interest of child is plainly furthered by nurturing the child's relationship with both parents that is why the judges are reluctant to condone any behavior by either party that tends to diminish child's relationship with the other party. Judges have reliance on the friendly party, who is mature enough to separate interpersonal difficulties from parenting role; who is more capable to control the hostility and conflicts between spouses after divorce to communicate and cooperate in child care; who is more willing to facilitate and support for non custodial parent's involvement. Any conduct like snatching the child, interfering visitation would cast serious doubt of fit custodial parent. 


\section{d. Time spend with the child}

Nowadays in China, with more couples both engaged in work, children are more often being left to grandparents, day care, or even babysitter; nevertheless, neither parent should be blamed or accused for doing so to provide better material benefit for children. However, it is beyond controversy that parents need to have sufficient time spent with children to build the physical and psychological ties, otherwise, they may feel being neglected or abandoned. Facing with paradoxical reality, most judges declare that they favor the party who has flexible working schedules and less long term business travel to avoid parent absence and ensure the constant child-parent connection.

e. Bad habits. Bad habits including insobriety, drug addiction and gamble are not only demerits of their own characters, but also considered lacking family responsibility by indulge oneself in harsh situation involved with financial crisis, legal problems, mental disorders and poor health condition. Apart from interrupted normal development, the children who exposed to addicted parents, suffering emotionally and socially, have higher risk of engaging in delinquent behavior and experiencing depression. Obviously, none judge would award custody to notorious addicted parent in rehab; as for feason who has rehabilitated, the situation is quite argumentative. Some judges hold that as long as the feason ultimately quit the addiction, he deserves to be treated as normal individual without prejudice, and that is how we pave the road back to right way for delinquent. Meanwhile, child is not responsible for the misconduct of parent, and being cut down the bond with parent merely to punish him for past sins. However majority of the judges believe it seems fair to place child away from the stressors to avoid insecurity and anxiety, moreover, custody decision is based on the only criterion--best interest of child, and other irrelevant goals shouldn't taken into consideration.

\section{Domestic violence.}

Domestic violence is no longer a private matter between the parents, and has become a critical consideration in child custody decision. It is generally recognized by judges that children witnessed or experienced domestic violence would suffer deep and profound harms in future. Therefore, most of the judges would hesitate to grant custody to abusive parent, unless other positive factors far outweigh the drawback.

a. Abuse towards spouse. In a civilized society any child has the basic civil right to live in physical security, and free from the threat of brute force. Although the child might not be the direct victim, residing with a parent has the history of committing domestic abuse is highly against interest of him.

b. Abuse towards child. China has the long history of accepting that parents have the right to discipline their children that involves physical punishment. When determine the fact of child abuse, it is necessary to distinguish appropriate discipline and abuse, pursuant to the amount and extent of the physical punishment. c. Mental abuse, a continuous conduct including but not limited to diction, expression and other nonviolent behaviors towards the spouse or child that causes embarrassment, anguish humiliation and ignorance, endangering the mental and physical health, results in miserable and even unendurable life.

\section{Each parent's previous care taking involvement.}

Family ties need not depend upon the biological or legal relationships but rather are based on day to day interaction, companionship, and shared experiences. On this account, various of functions performed by each caregiver should be assessed by the time and quality before divorce. Encouraging the primary caretaker, judges preserve main attachments between child and parent as well as acknowledging the predivorce devotion to family maintenance and child rearing. Some states of American have adopted specific guideline for judges to value the previous contribution to child, and as for as author concerned, a list of sub-factors should be measured including, but not limited to[13]:

(1)Preparing the meals; (2)Purchasing the clothes and care of dressing; (3) Medical care; (4) Transporting child; (5) Arranging extracurricular activities and other social activities; 6) Sleeping and bedtime with child; (7)Education, give advice in study; (8) Disciplining the general manners and other social morality.

\section{Miscellaneous factors}

\section{a. Child desire}

The child's preference for a given parent is important but not conclusive, since juvenile is not mature enough and susceptible to superficial facts, in some extreme scenario can easily be manipulated by either party. According to the judicial interpretation of Supreme Court, if any custody disputes arise for the child over 10 years old, the willingness of child shall be taken into consideration. Apart from the legal praesumptio, in practice the weight a judge attaches to the child's wish increases with the age as follow:

$$
\begin{gathered}
A(x)=\left\{\begin{array}{cc}
0 & \text { if } 0 \leq x \leq 0.5 \\
\left(1+\left(\frac{x-0.5}{0.05}\right)^{-2}\right)^{-1} & \text { if } 0.5 \leq x \leq 1
\end{array}\right. \\
B(x)=\left\{\begin{array}{cc}
0 & \text { if } 0 \leq x \leq 0.5 \\
\left(1+\left(\frac{x-0.5}{0.05}\right)^{-2}\right)^{-1} & \text { if } 0.5 \leq x \leq 1
\end{array}\right.
\end{gathered}
$$

\section{b. Child found not to be natural child of one parent}

The fact that contested child found not to be natural child of one parent would sway the decision of judges. The blood ties between parent and child as well as parental instincts are biological reasons with overwhelming advantages over the non biological parent. Psychologically speaking, however, a qualified parent is whom the child attached a particular distinctive set of feelings, and this emotional tie cannot de discounted or ignored for simple biological reason, otherwise the continuous emotional bond would be disrupted[12-14]. 


\section{c. Sibling}

Sibling problem in Chinese family is considerably rare in light of one child policy, but still inevitable especially in rural area. Most of judges declared that siblings are encouraged to keep together as any child is entitled to benefit from the constant association with another, unless certain circumstances indicate that separation based on children's individual needs may better promote the long term interest.

\section{d. Relationship with other important relatives}

Child-parent relationship can never be considered in vacuum, when the child residing with certain parent who has other important social relationships. For those live in the extended family, the attitudes of other family members are concerned by the judges; for those have remarried or have fiancé, whether the child can be supported by stepparent or stepparent-to-be also addresses high attention from judge before making a decision. In addition to the legal circumstance mentioned above, judges also prefer the party whose influential relatives are desirable to reside with the child and are willing to make an effort in help raising the child whereas depreciate the party who is immersed in high level of acrimony with others to prevent child from insecurity and apprehension[14-16].

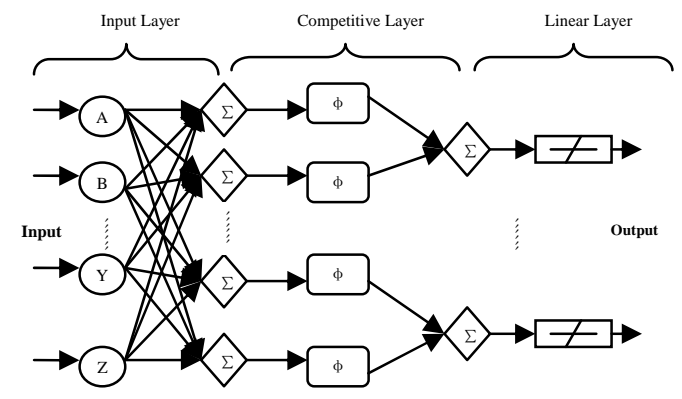

Figure 2. Struct of LVQ Neural Network

Processed by Neural Network[17-18], the final score of individual parent indicates different arrangements. If one party is far more superior to the other, granting the sole custody to this party is considered as a matter of course. If both parties are fit with similar parenting condition, thus depriving custody of either party seems cruel and detrimental to child's development, we suggest the court mediation to attempt the joint custody first. Under current Chinese marital law, though, joint custody is not statutory arrangement, which only feasible for parents agreed to do so, it could benefit children by continuing contact with both parents. In case that ex spouses are able to separate their interpersonal dissatisfaction and even hostility from parenting role, the communication and co-operating between parents, being doable after the mediation by Wisdom of Solomon, ensure the precondition of joint custody. While, for those failed coparenting after mediation, there is no shirking the responsibility will the judge award sole custody to better one despite slight advantages.

\section{Discussion OF RESUlTS}

In order to testify this paper's method is superior, we use other model to compare. By contrast, the efficiency of LVQ neural network approach is better than other neural network.

The quality of simulate result effect should be evaluated objectively by testing data sets.

It indicates our model is fitter for the children custody decision making case in city in china, by reason of the studying samples are all from city. As a whole our model is considered as the aid for judge and children custody disputes party.

\section{CONCLUSIONS}

In order to make decision making for the children custody scientifically, a new model which adopting latest marital law of PRC and LVQ neural network was proposed. Firstly, all up-to-dated clauses involved with custody disputes in divorce were quantified to obtain related set elements. Then the LVQ neural network was applied to construct a model for children custody disputes weight vector analysis on the set elements. Ultimately, the weight vector close to decision boundaries between classes contributes to the classification performance. Accordingly, the performance of the LVQ by generating weight vectors close to decision boundaries is higher. Further investigations on the Legal expert based on pattern recognition are left for future work.

\section{REFERENCES}

[1] C. J. A. Beck, M. E. Walsh, M. B. Mechanic, C. S. Taylor.Mediator Assessment, Documentation, and Disposition of Child Custody Cases Involving Intimate Partner Abuse: A Naturalistic Evaluation of One County’s Practices, Law Hum Behav (2010) 34:227-240

[2] E. E. Wynne, JD.Children's Rights and the Biological Bias in Biological Parent Versus Third-Party Custody Disputes. Child Psychiatry and Human Development, Vol27(3),pp179-191. Spring 1997

[3] E. Willemsen, R. Andrews, B. Karlin, and M. Willemsen.The Ethics of the Child Custody Process: Are the American Law Institute's Guidelines the Answer? Child and Adolescent Social Work Journal, Vol. 22(2), April 2005, pp.183-211

[4] M. Cancian and D. Meyer. Who gets custody? Demography, 1998.vol35(2): 147-157

[5] J. B. Rohrbaug. A Comprehensive Guide to Child Custody Evaluations: Mental Health and Legal Perspectives. Spring, 2008, pp.43-56

[6] V. Elizabeth, N. Gavey, J. Tolmie. Between a Rock and a Hard Place: Resident Mothers and the Moral Dilemmas they Face During.Fem Leg Stud (2010) 18:253-274.

[7] S. B. Kamerman.Child, Family, and State: The Relationship Between Family Policy and Social Protection Policy.Children's Well-Being: Indicators and Research,(2010) 18:429-437

[8] Seongwon Cho and Jaemin Kim,Iris Recognition Using LVQ Neural Network.Lecture Notes in Computer Science(LNCS) 3972, pp. 26-33, 2006.

[9] Jing-Xin Wang, Zhi-Ying Wang, and Kui-Dai.Intrusion Alert Analysis Based on PCA and the LVQ Neural Network.Lecture Notes in Computer Science(LNCS) 4234, pp. 217-224, 2006. 
[10] M. K. Bashar, N. Ohnishi, T. Matsumoto, Y. Takeuchi, H. Kudo, K. Agusa.Image retrieval by pattern categorization using wavelet domain perceptual features with LVQ neural network.Pattern Recognition Letters 26 (2005) 2315-2335..

[11] Marital Law of PRC on http://www.npc.gov.cn

[12] Interpretation on child custody disputes of the Supreme People's Court of PRC on http://www.court.gov.cn

[13] F. Burton: Family Law. (Cavendish Publishing Limited, Great Britan 2003).

[14] R.E. Oliphant, N.V. Steegh: Work of the Family Lawyer. (Aspen Publishers, New York,2004).
[15] L.J. Harris; L.E. Teitelbaum; J. Carbone: Family Law.( Aspen Publishers, New York,2005)

[16] Alison Diduck: Law’s Family. (LexisNexis UK,2003).

[17] Oskamp and Lauritsen: AI in law and practice? So far, not much, Artificial intelligence and law. Vol. 10(2002),p227-236.

[18] C. Stevens, V. Barot, and J. Carter:The Next Generation of Legal Expert Systems-New Dawn or False Dawn?, Research and Development in Intelligent Systems XXVII,Springer-Verlag London 2011. 